\title{
Come On Up for the Rising: A Review of Biglan's Rebooting Capitalism
}

\author{
Brian D. Katz ${ }^{1} \cdot$ Stephanie C. Chan ${ }^{1}$ (D) - Daniel Schmidt ${ }^{1} \cdot$ Melinda Miller $^{1}$. \\ Ruth Anne Rehfeldt ${ }^{1}$ (iD
}

Accepted: 17 February 2021/ Published online: 31 March 2021

(C) Association for Behavior Analysis International 2021

\begin{abstract}
In Rebooting Capitalism: How We Can Forge a Society that Works for Everyone, Anthony Biglan (2020) explains that a free-market and capitalist narrative, sculpted by a coalition of the extremely wealthy, has led to a commonly held myth that the pursuit of individual wealth will improve the overall well-being of the populous. Instead, our current economic system and public policies have resulted in cultural practices that increase wealth inequality, incite racial tensions, and destroy the natural world. The book functions as a call to arms for behavior analysts to join a coalition of interdisciplinary professionals with a like-minded mission of creating a nurturing form of capitalism, grounded in behavior science, that improves the quality of life for all people.
\end{abstract}

Keywords evolutionary science $\cdot$ cultural practices · acceptance and commitment training capitalism

Rebooting Capitalism by Anthony Biglan (2020) was published during a period of global unrest, exacerbated by the outbreak of Coronavirus Disease 2019 (COVID-19) and a period of racial reckoning in the United States. In the foreword, evolutionary biologist David Sloan Wilson details how the COVID-19 pandemic evoked an increased sense of urgency and aggravated preexisting global and national tensions. In addition, most states within the United States enacted stay-at-home orders, which significantly affected the well-being of society. Stay-at-home orders contributed to civil unrest by introducing several stressors, including economic instability, uncertainty regarding education, and public health concerns, and amplified divisions between

Brian D. Katz

bkatz@ego.thechicagoschool.edu

1 The Chicago School of Professional Psychology, Chicago, 325 North Wells Street, Chicago,

IL 60654, USA 
political parties in the United States. In addition, the brutal murder of George Floyd and parallel instances of racially charged police violence evoked national attention and widespread protest. Eighty-three percent of Americans stated that the country's future is a significant source of stress (American Psychological Association, 2020). We are now presented with an opportunity to examine how the current state of our nation and global community have come to pass. Through this process of reflection, the time is ripe for behavior scientists to rise up and contribute to systemic change - the call to action in Rebooting Capitalism.

It is relevant to conceptualize our current societal problems within the lens of evolutionary science. In Science and Human Behavior (1953), Skinner delineated multiple levels of selection that influence human behavior: phylogenic selection, ontogenic selection, and "a third kind of selection which applies to cultural practices" (p. 430). Regarding the mechanisms involved in cultural selection, Holth (2016) made clear that group cultural practices are selected in a fashion similar to Darwin's natural selection. In a parallel manner, it is the social environment that selects cultural practices. Towards the end of Skinner's life - equipped with knowledge of the mechanisms of selection - he wrote that the world was in a critical state and lamented the fact that behavior scientists had not done more to shape cultural practices (Skinner, 1987).

Yet, all is not lost, because Skinner's dream to tailor cultural practices through behavior science has carried on in the field of prevention science. According to the National Prevention Science Coalition (NPSC), prevention science "focuses on the development of evidence-based strategies that reduce risk factors and enhance protective factors to improve the health and well-being of individuals, families, and communities" (NPSC Coalition, n.d.). Biglan (2018) reiterated, "the ultimate goal of prevention science is to assist societies in ensuring the social, psychological, and physical well-being of every member of society." Biglan explained that we can shift cultural practices and improve overall outcomes for individuals, such as academic achievement, social and emotional competence, psychological and behavioral problems, and physical health by altering environmental distal influences (e.g., income and resources, social cohesion, and physical environment), and proximal influences (e.g., family influences, school influences, and peer influences). The success of this model is exemplified in the prevention of tobacco use through community-wide prevention programs. For instance, Biglan, Ary, Smolkowski, Duncan, and Black (2000) conducted a randomized controlled trial of a multicomponent, school-based community intervention to prevent adolescent tobacco use. Results showed that the intervention was effective at reducing the prevalence of tobacco, alcohol, and marijuana use among adolescents. In a similar fashion, Wilson, O'Brien, and Sesma (2009) conceptualized prosocial behavior through the lens of evolutionary theory and analyzed altruism on a city-wide scale in the Binghampton Neighborhood Project. Through statistical analyses and visual mapping of several dependent variables, Wilson et al. concluded that those with the most social support engage in the highest levels of prosocial behavior. In other words, prosociality as a behavioral strategy to improve evolutionary success can be summed up as "those who give to others, get from others" (p. 198).

Some influential social scientists, such as Pinker (2018) and Harari (2014), argue that we ought to interpret the history of humanity through a lens of progress; that as of the $21^{\text {st }}$ century, we have made our world a more enriched, comfortable, and 
inhabitable place. We, on the other hand, argue that evolution does not necessitate progress, and we can do better. In a world in which communities consistently struggle with low income, inequality, deteriorating health, a worldwide pandemic, omnipresent college debt, intensified natural disasters due to climate change, astronomical rates of incarceration, and an untrustworthy media, there are certainly sectors of society in which improvements can be made. We as behavior analysts possess a unique skillset in which our systematic science of behavior has provided us the ability to describe, predict, and influence behavior. Thus, we have the keys to the kingdom. Rebooting Capitalism functions as a call to arms and beckons behavior analysts to join the Values to Action Coalition so that we might facilitate the implementation of behavior science on an unprecedented scale. If now is not the time, when will it be?

\section{Overview}

Biglan (2020) opens Chapter 1 with an overview of evolutionary theory to explain how our current society came to operate, and to introduce the notion that behavior science can be utilized to guide intentional change towards a new, more nurturing form of capitalism. Although evolution is commonly discussed in terms of phylogenic selection, Biglan emphasizes that "any process that has variation and a mechanism that selects a subset of variants is an evolutionary process," which includes the ontogenically selected behavior of individual organisms and the cultural practices of groups and corporations (p. 18). Through this discussion of selection by consequences at different levels (i.e., multilevel selection), the works of evolutionary biologist David Sloan Wilson are presented and illuminate how each level, or unit of life, interact with and result in the societal practices and problems we observe today - an analysis similar to that of Glenn et al. (2016). Biglan explains that Wilson's view of multilevel selection is critical to understanding the evolution and maintenance of harmful corporate practices (e.g., tobacco, food, and pharmaceutical industries). These deleterious corporate practices have contributed to increases in well-being for a minority of individuals, and significant decreases in well-being for the overwhelming majority. Furthermore, profit and wealth maximization are distinguished as the predominate selecting consequences of our current system of capitalism and led to the development of what is referred to as the "Conservative Billionaire Coalition" (p. 29). Biglan provides two ways to target and change these selecting consequences, including fining companies for harmful practices (i.e., the no-profit principle) and increasing the profitability of alternative beneficial practices. However, Biglan addresses the notion that simply altering these consequences is not enough. That is, to evolve a society that is prosocial (i.e., most people are working to enhance the well-being of their group), people need to live in a nurturing environment that cultivates prosocial values and actions.

Even before the turbulent events of 2020, the well-being of Americans and global citizens were deteriorating. In evolutionary terms, Biglan, Johansson, Ryzin, \& Embry (2020) explained that human developmental trajectories are altered by environmental contexts. In particular, environments that contain high levels of aversive control, conflict, and stress lead to a category of development deemed a "fast life" trajectory (p. 5). In contrast, a "slow life" trajectory is comprised of nurturing environments, selfregulation, and psychological flexibility (p. 5). Biglan et al. (2020) cautioned that these 
"fast life" environments lead to increased levels of impulsivity, risk-taking, antisocial and violent behavior, academic struggles, and increased likelihood of mental health problems. Perhaps even more costly, "fast life" trajectories also predict poor physiological outcomes such as "the development of inflammatory processes that contribute to metabolic syndrome, diabetes, cardiovascular disease, and ultimately premature death" (p. 5). Biglan (2020) argues that due to our global free-market capitalist system we moved away from sustainable and nurturing environments, and our overall welfare has been compromised. Applicable to the "fast life" paradigm, Grant (2010) explained that Americans engage in overconsumption of goods and products, and likewise, most developed economies consume unneeded luxury items. According to Grant, overconsumption is a function of competitive contingencies and antithetical to sustainability. Contingencies of competition and environments featuring aversive control have led to contexts that are damaging to individuals and to the culture at large. Furthermore, our current U.S. legal system, and others around the globe, contain a paucity of public policies and laws promoting the well-being of all citizens. In contrast, Sanguinetti (2012) informed that experimental and intentional communities utilizing cultural engineering seek to disrupt this damaging "fast life" trajectory by limiting factors such as suburban sprawl, environmental degradation, and a lack of physical activity. In short, these are communities that have been culturally designed through public policy and urban planning with an aim to build nurturing and healthy environments.

In Chapter 2, Biglan discusses people's psychological readiness to engage in committed action towards advancing a more nurturing society. Two common barriers that "get in the way of taking effective action to promote the kind of society we want" are presented in the form of avoidance of aversive private events surrounding our current environments and the fact that "we simply don't know what to do" (p. 40). With support from the works of Hayes on psychological flexibility and Acceptance and Commitment Training (ACT; Hayes, 2019; Hayes \& Smith, 2005), Biglan provides an overview of the behavioral repertoires that can be cultivated to target such barriers (pp. 40-46). According to Hayes (2019), "Psychological flexibility is the ability to feel and think with openness, to attend voluntarily to your experience of the present moment, and to move your life in directions that are important to you, building habits that allow you to live life in accordance with your values and aspirations. It's about learning not to turn away from what is painful, instead turning toward your suffering in order to live a life full of meaning and purpose" (p. 15). ACT builds behavioral repertoires that together contribute to psychological flexibility. Thus, Biglan introduces the term "personal pragmatism," in which we "persist or change our behaviors not because of what our minds tell us but in light of what seems to be working in living our values" (p. 40). The chapter concludes with evidence that prejudice and discrimination have been, and can be, effectively intervened upon at both the individual and group level through interventions such as cooperative learning and ACT in school and organizational settings. Last, Biglan offers suggestions for what individuals can do to advocate for policies and organizations that result in change towards a more nurturing society.

In Chapter 3, Biglan (2020) outlines a five-component framework designed to create a kinder and more compassionate society. The first component consists of establishing an operational definition of the society that we want, with the pursuit of valuing everyone's well-being rather than that of a select few in mind. This definition is 
supported by the "enormous knowledge that has accumulated about what human beings need to thrive" (p. 66). The critical features of such a society have been identified by Biglan through the growing "evonomics" movement (the use of evolutionary science to conceptualize capitalism and human society), as revealed in Biglan's book The Nurture Effect (2015). The second component in the framework consists of clarifying how prosocial behavior is cultivated in individuals. Biglan debunks notions that human beings are inherently self-serving by citing studies by evolutionary scientists illustrating how humans indeed cooperate and work for the betterment of the group given the right environmental conditions. The same evolutionary perspective can be applied to the development of antisocial behavior. Although antisocial behaviors are acquired via the social learning processes, Biglan reiterates that individuals can still choose to engage in psychologically flexible behaviors that are consistent with prosocial values rather than waiting for a societal shift in values to occur. Future research might examine the conditions under which prosocial behavior is most likely to occur, and, if identified, behavior scientists may be able to modify socially significant group practices (e.g., acceptance of vaccinations, use of personal protective equipment, and mask-wearing).The third component of the framework involves utilizing incidence and prevalence data on public health to evaluate how effective our pursuits are in making a more nurturing society. Lastly, the fourth and fifth parts of the framework depict what conditions are needed to influence and monitor harmful corporate practices.

In addition to the framework charted by Biglan (2020), other scholars have also surveyed systems of prosociality and nurturance. For instance, Diller and Lattal (2008) provided an in-depth assessment of Radical Behaviorism and Buddhism by discussing areas of consilience between the two domains. For instance, both systems take a pragmatic approach towards human suffering. Furthermore, mindfulness (interacting with stimuli in ways that are nonevaluative and presentfocused with sharpened discriminative control) has been integrated into behavior change technologies such as ACT and has been conceptually analyzed in basic science (Hayes \& Plumb, 2007). However, the practice of mindfulness stems from the deep history of Buddhism and is prescribed within the Eightfold Path, a set of practices aimed at improving the human condition. Diller and Lattal (2008) argue that a thorough analysis of how both Buddhism and Radical Behaviorism interrelate may lead to an improved understanding of both and allow for comparison of other ostensibly incongruent philosophical systems. Like behavior analysis, Buddhism presents functional means for improving the human condition, despite some philosophical differences (e.g., determinism vs. the possibility of free will and achieving socially significant change vs. achieving nirvana). Buddhism also emphasizes a slower paced, mindful society that cultivates caring and nurturance for all members. By exploring connections between behavior science and Buddhism, a "slow life" trajectory may be obtained, thus preventing all of the ills of "fast life" trajectories.

Chapter 4 details the need for a coalition of organizations dedicated to building a society that works for the well-being of everyone. Biglan (2020) explains that today's society is shaped and maintained by the laser-focused, coordinated actions of the extremely wealthy (p. 82). This conservative billionaire coalition forges an unprecedented level of cooperation to foster support for free-market economic theory, and thus, 
the coalition accomplishes self-seeking successes but does not act in the interest of the larger society. To bring about positive change and prosperity for all, Biglan suggests the need for a new coalition-the Values to Action Coalition. He cites three reasons for the development of a multisector coalition: there are interconnections among societal problems, there are fundamental conditions that underlie societal ills (e.g., poverty and discrimination), and speaking with one unified voice will lead to a greater likelihood of success in creating a collaborative community that works for everyone (pp. 84-91). Furthermore, Biglan suggests that the Values to Action Coalition utilize behavior science to inform public policy, as behavior scientists possess the knowledge and skills to construct environments that will allow all individuals and groups to thrive (p. 91). Of particular value is culturobehavior science, a growing area of emphasis in behavior analysis focused upon describing and predicting the interlocking meta-contingencies that influence collective human behaviors (see Cihon \& Mattiani, 2019).

In Chapter 5, Biglan (2020) establishes that business and capitalism can indeed function as nurturing entities, and he provides a structure for how this can be accomplished on a wider scale. It is possible to achieve a nurturing business community, so long as practices result not only in profits, but also benefits to stakeholders (e.g., customers, employers, investors, suppliers and society). The author suggests the use of B-Corps (certified corporations that meet standards of social and environmental performance and transparency) and highlights the movement called conscious capitalism, which promotes "purpose-driven business" and affirms the well-being of all stakeholders. By valuing people (e.g., workers, suppliers, consumers), businesses can develop a collaborative environment that is aligned with community building values. Finally, businesses can utilize behavior science to promote adaptive work-related behaviors. Since the 1960s, organizational behavior management (OBM) has used the principles of behavior analysis to improve employee performance (Daniels, 1989; Wine \& Pritchard, 2018). The technologies harnessed in OBM are nurturing in that they avoid aversive control and utilize appetitive consequences to alter behavior. In addition to enhanced management practices, Biglan (2020) provides several suggestions for the everyday consumer: (1) support business that align with your values, (2) work for a company that aligns with your values, and (3) invest in companies that are values-driven and do not engage in harmful business practices (pp. 109-110).

In Chapter 6, Biglan (2020) declares the U.S. public health system to be "broken" and the worst of any developed nation, as evidenced by a multitude of metrics including inordinate amounts of spending per capita, infant mortality rates, and reduced life expectancies for minority groups (p. 114). The author analyzes the history of our broken system and points to three causes. First, the U.S. health-care industry evolved to maximize profits, in the context of free-market capitalism, with a paucity of systematically delivered positive reinforcement for improved health outcomes. Second, the forprofit insurance industry evolved to maximize profits and halt efforts to create a singlepayer system. Third, conservative groups became "obsessed" with discontinuing the Affordable Care Act (ACA), a law that increased health-care coverage for 20 million Americans. Biglan suggested that potential sources of this "obsession" included an establishing operation to maximize profits for both health-care providers and insurance companies (pp. 114-116); providing increased coverage, especially for Americans with 
preexisting medical conditions, may serve as an abolishing operation to support of ACA due to the potential loss in profits. Furthermore, Biglan explains that the U.S. public health system has largely ignored the social determinants of health, despite research suggesting that the largest portion of premature deaths can be attributed to unhealthful behaviors, and that stressful social environments, "are the root of most of our health problems" (p. 119). This theme resonates with the work of Wilson (2016), who suggested that we form public policy based upon indicators of quality of life (QoL), or the notion that human health, education, freedom from harm, psychological well-being, and ultimately the sustainability of the planet can be measured and used as an alternative to economic measures such as gross domestic product. To improve the QoL of citizens given the ever-increasing costs of health care, a provision within the ACA can be utilized on a wider scale. The provision states that employers may use up to $30 \%$ of the total amount of employees' health insurance premiums to provide outcome-based wellness incentives. With the aid of behavioral economics, incentives can be formulated that result in real shifts in behavior (Volpp, Asch, Galvin, \& Loewenstein, 2011).

In Chapter 7, Biglan (2020) examines the ways in which institutions of higher education promote laissez-faire economic theories that deteriorate nurturing environments and prosociality. A movement began in the early 1970s to lobby and persuade U.S. universities to promote "free market theories and values" (p. 139). This lobbying effort followed the influential 1971 Powell Memo-a memorandum written by an associate justice of the U.S. Supreme Court regarding the urgency of conservative business interests reexerting influence in American society. This initiative resulted in a diaspora, into all sectors of society, of graduates immersed in free-market theory. The author explains that to reverse this trend, university departments, including law, business, and psychology, must work toward developing nurturing societies by incorporating content on behavior science into curricula. Biglan (2020) proposes three reforms to higher education. First, institutions of higher education must focus on solving problems that endanger the nation and the world. However, funding must be directed towards this aim. As of now, less than $6 \%$ of federal funding is allocated to behavior science and social science research (p. 142). Next, the behavior and evolutionary sciences should be integrated into departments such as law, economics, computer science, and business. Last, although it is possible for higher education to be at the forefront of societal change, initiatives that enact effective policies, programs and procedures aimed at improving people's well-being are required.

Biglan discusses the detriment to well-being caused by the country's current criminal justice system in Chapter 8 . With the second highest rate of incarceration among all nations and significant racial disparity among those imprisoned, Biglan (2020) states that the current U.S. criminal justice system has failed its citizens. Biglan condemns a system that, instead of adopting a preventative approach to criminality, relies upon punishment and aversive control. These punitive approaches, conducted in the name of deterrence, have incarcerated individuals, especially monitories, for inordinate amounts of time, and have led to the breakup of families and escalation of poverty. As a result, the recidivism rate in the United States is extraordinarily high at $76.6 \%$ (p. 157). In addition, prisons have become increasingly privatized, which may contribute to the relatively high rates of relapse. Biglan suggests that efforts be put towards rehabilitation, environment change, and skill-building. In particular, he proposes preventative 
prosocial and community-based interventions such as the good behavior game and explores corresponding changes in public policies. These recommendations are consistent with Holland's (1978) arguments. Holland contended that behavior analysts should focus on making changes at the level of cultural systems rather than at the level of the individual. He argued that behavior analysts must work to alter "the system, not the victim" (p. 170), and suggested that we look inwards to assess the degree to which our programmed contingencies maintain social inequality and current class structures. However, on an individual level, Biglan suggests that citizens advocate for the utilization of evidence-based rehabilitation practices and the elimination of laws that impede postincarceration adjustment (Biglan, 2020, p. 166).

Chapter 9 discusses how social media can contribute to environments of competition and hostility. Studies have shown a positive correlation between addictive social media use and depression, anxiety, and high stress levels (Brailovskaia, Schillack, \& Margraf, 2020). For example, internet trolling, a malicious online behavior in which a person creates discord and attempts to disrupt an online community, has led to emotional distress in a reported $40 \%$ of online users (Cheng, Bernstein, Danescu-Niculescu-Mizil, \& Leskovec, 2017, p. 3). Beyond this harm, Biglan (2020) asserts that hate and division between groups are exacerbated by the evolution of verbal communities on social media who emit conspiratorial and extreme verbal behavior - capable of provoking violence - and the spread of micro-targeted disinformation campaigns led by political organizations (e.g., Cambridge Analytica in 2016). Meanwhile, internet monopolies such as Facebook, Google, Amazon, or Apple evolved with the sole purpose of gaining profits and growing their user bases. An effect of these contingencies is the collection of colossal amounts of data on the behaviors of billions of people. The function of this pervasive data collection is to enhance the effectiveness of advertising and sales through micro-targeting, much like political disinformation campaigns. It is unfortunate that lobbying efforts by leaders of Silicon Valley monopolies have made little effort to control these practices and have instead supported the environments in which microtargeted disinformation campaigns can prey upon the vulnerable to "stoke their rage" (p. 182).

Biglan (2020) offers several ideas for overcoming these challenges, including the creation of laws on monopolies applicable to internet titans, campaigns to elucidate microtargeting, and increased funding toward research that investigates the impact of digital marketing on public health. Biglan cautions that efforts to limit hate speech may serve as establishing operations that function to increase rates of antisocial behavior. Thus, the most important counteraction to hate speech, conspiratorial verbal communities, and proliferation of disinformation is to develop competing contingencies in which prosocial communications are emitted at higher rates and reinforced on denser schedules of reinforcement. Biglan conceptualizes this movement as being akin to a race between the forces of division and prosociality. This notion is analogous to Vollmer's (2018) conceptualization of differential reinforcement as a "way of life." Media groups recently banned President Trump's personal accounts, a reaction to his verbal behavior relating to the riots at the capital building on January 6 (Conger \& Isacc, 2021). More can be done, however. Media outlets can differentially reinforce prosocial communication aimed at bringing people together by providing differential durations and rates of media coverage. 
Biglan (2020) emphasizes the urgency of our climate crisis in Chapter 10. According to NASA, there is unequivocal scientific evidence pointing to human activity as the cause of global warming. Since the 1950s, the rate of warming has been unprecedented and resulted in an increased number of extreme weather events (National Aeronautics and Space Administration, 2019). The wildfires plaguing the American West in fall 2020 are likely a result of global climate change. The degradation of our natural environment, leading to increased frequency and severity of natural disasters, is another important variable in a stressful and fast modern life. Environmental scientists such as Ehrlich and Kennedy (2005) have struggled to find ways to change the relevant human behaviors and Biglan (2016) reiterates that behavior science has much to provide in the area of cultural selection. The metacontingencies that maintain the actions of organizations, such as the oil industry, can be analyzed through experimental analyses of cultural practices. Following a systematic analysis of the consequences that maintain the cultural practices of organizations and governments, behavior scientists may be able to recommend impactful and practical strategies to the environmental science community.

In this chapter, Biglan provides broad examples as to how organizations make profits while simultaneously emitting greenhouse gases and deteriorating the environment. He also explains why humans seemingly ignore the long-term dangers of climate change and have yet to take effective, immediate action. Solutions to this dilemma include the application of Relational Frame Theory (RFT) in developing "verbally constructed descriptions" of the future to motivate and evoke public action (p. 203). The author encourages research investigating ways to reduce carbon footprints and persuade governments to implement effective policies. At the end of the chapter, largescale interdisciplinary programs are proposed, including policy development at the government level, influencing carbon footprints of households and organizations, and community intervention.

In the concluding chapter, the author elaborates upon how a political system can work towards the well-being of all citizens. As a self-proclaimed moderate Democrat, Biglan (2020) analyzes the events that led to the Democratic Party's loss in the 2016 presidential election. In particular, he cites policies enacted by the Clinton and Obama administrations that functioned to "embrace Wall Street" and hollow out the middle class (p. 216). These policies were in support of free-market theory and resulted in further disparity of wealth. The consequence was the election of the Trump administration of whom Biglan pronounces, "we have run out of adjectives to describe how a terrible a president he is" (p. 221). Clearly dissatisfied with Trump's presidency, and in search of solutions, the author suggests the creation of a political movement on a scale similar to that of the Progressive Era or the New Deal; a system that works for the well-being of all. Biglan suggests several reforms to address immediate concerns of people including an implementation of fundamental reforms to fulfill societal values, a revocation of voter suppression laws, and the reduction of gerrymandering. Biglan also advocates for widespread policy reform and the use of science to evaluate the effects of government policies. Although the commentary in this chapter may be perceived by some as partisan, the reflections and solutions are inspiring. As Biglan states, the United States has developed increased "selfishness, poverty, economic inequality, and 
discrimination" in the past half century (p. 237). Government policies play a crucial role in establishing cultural values and practices that benefit the well-being of all.

Malott (2016) informed that we can learn much about behavior by studying political leaders. She identified the critical characteristics of effective leaders to include (1) commitment to principle, (2) independence, (3) resilience, and (4) consistency. Moreover, Malott (2016) examined how leaders function as a group through interlocking contingencies and nonreplicable interrelations, using the Cold War as an example. The result of multiple leaders operating under metacontingencies can be regarded as cultural cusps - aggregate products that have far-reaching and significant cultural change. The current government system in the United States often utilizes aversive control to stoke division and fear in a presupposed attempt to gain reelection of leaders. We might ask, is it possible that recent administrations have created cultural cusps that may negatively affect our society and cause the deterioration of public health? For instance, what will be the far-reaching consequences of relating a majority news media to "fake news?" Or, how might the relation of mail-in ballots as being "more untrustworthy" than in-person ballots influence future elections? Finally, how might the framing of climate change as a "Chinese hoax" affect future environmental policies?

\section{Keys to the Kingdom: Scaling Up}

Biglan (2020) functions as a call to arms and provides a comprehensive blueprint as to how we-as individuals - can contribute to the evolution of a society that cultivates caring and nurturance for all people. In the wake of global unrest, teaching people to value themselves and others, through what David Sloan Wilson refers to as "consilience" (i.e., the convergence of approaches to explain the natural world), may be critical (Biglan et al. 2020; Wilson, 2012). Biglan et al. (2020) detailed how prevention sciences have targeted behavioral change processes of scaling up and scaling out to achieve consilience and the evolution of more caring, nurturing societies. Scaling up refers "to the process of moving from an individually focused intervention to the application or dissemination of that intervention to affect an entire population," and scaling out involves "creating an impact in sectors of society other than the one in which the intervention or practice originated" (pp. 2-3).

Rebooting Capitalism calls for scaled up and scaled out applications of behavioral interventions such as the Good Behavior Game and ACT. However, there are many other opportunities for scaled up behavioral interventions in addition to these two. For instance, behavior science can be utilized to decrease racism and prejudice. Following the death of George Floyd and racial unrest of 2020, Mattaini and Rehfeldt (2020) reviewed the ways in which the "dark side" of language and relational learning can produce racism, prejudice, and bias. They described the history of aggressive policing and the profound effect it has had upon people of color. Mattaini and Rehfeldt suggested several systematic cultural-level interventions to change the practices within police forces. These include reducing job stressors, ACT and behavior skills training to reduce implicit bias, community alternatives for policing, nonviolent social action, and advocacy for specific public policy changes. Likewise, Matsuda, Garcia, Catagnus, and Brandt (2020) reviewed behavior analytic research that has been conducted on the topic 
of racism and reported that very little has been done to date. The authors suggested that behavior scientists can contribute to the reduction of systemic racism through investigations of relational framing. The experimental literature has shown that relational training can function to reduce racial bias (Dixon \& Lemke, 2007; Mizael, de Almeida, Silveira, \& de Rose, 2016); however, in some cases, preexisting relations or rules can make forming new contradictory relations difficult (Dixon, Rehfeldt, Zlomke, \& Robinson, 2006). According to Matsuda et al. (2020), ACT is a promising approach for reducing racist behaviors and prejudices. In particular, mindfulness-based interventions that teach people to recognize and notice prejudiced thoughts have been implemented to reduce implicit race and age bias (Lueke \& Gibson, 2015, 2016). In addition, building repertoires of perspective-taking may ameliorate automatic expressions of racial bias. Todd, Bodenhausen, Richeson, and Galinsky (2011) found that indicators of racial bias on an implicit association test were reduced in undergraduate participants following a perspective-taking intervention, in which participants were instructed to change perspective between characters of different racial backgrounds presented in a video. Finally, values clarification interventions, which encourage individuals to contact oft-delayed and but powerful reinforcers, have shown potential in altering responses on prejudice-related questionnaires (Lillis \& Hayes, 2007).

Another area worthy of scaled-up and scaled-out application is the study of propaganda and the rhetoric of political leaders. Through functional content analysis (Rakos, 1993), behavior analysts can provide guidance to the populace. This can be done by identifying the function of political rhetoric much in the manner accomplished by Rakos. Rakos analyzed the stimulus functions of the George H. W. Bush administration's narrative published in the New York Times in the weeks leading up to the first Iraq War. Rakos found that verbal stimuli were delivered systematically by the Bush administration in a way that was intended to change public opinion for the war. Rakos concluded that the Bush administration's narrative functioned as propaganda because of the way relational frames were constructed in the rhetoric, thus garnering support for a military defense of Kuwait. Chan, Katz, Schmidt, and Rehfeldt (2020) recently reported a similar functional content analysis on two opposing speeches delivered by Presidents Obama and Trump on the issue of entering or exiting the Paris Climate Accord. The authors found that the two presidents differed in their use of reinforcer establishing augmentals (REAs) and punisher establishing augmentals (PEAs), thus revealing different motivational tactics to influence public opinion (Chan et al., 2020). The analysis of stimulus functions within political rhetoric, such as that conducted by Rakos (1993) and Chan et al. (2020), will aid the public in discriminating political intent. Similar analyses may also educate the citizenry as to how language moves people to action.

A third potential area for widespread behavior analytic intervention is in the domain of health and disease prevention. Rehfeldt and Tyndall (2021) surveyed the application of ACT in the prevention and treatment of chronic health conditions, with an eye toward the role that relational framing in public health messages plays in promoting prevention-related behaviors. Normand and Bober (2020) further suggested that behavior analysts scale up behavioral interventions in health and fitness by increasing our presence as heath coaches, a practice in which professionals provide individualized services to promote health, wellness, and lifestyle changes. Other behavioral interventions designed to promote healthy lifestyles and prevent disease also warrant mention. For example, experimental studies have analyzed how language effects health-related 
behaviors. These include an examination of the effects of verbal rules on patients' breast self-examinations (Meyerowitz \& Chaiken, 1987), and the identification of cancerous skin lesions as a function of verbal information about melanoma (Critchfield \& Reed, 2016).

\section{New Directions: Expanding Our Horizons}

A noteworthy feature of Biglan's (2020) text is its evocative function, as it serves to establish novel cultural-level lines of research, analysis and systems change. One sector of society that deserves increased analysis is the public education system. A chapter in Rebooting Capitalism is devoted to higher education, and a number of school practices are promoted frequently throughout the book. For instance, Biglan frequently promoted the Good Behavior Game and Positive Behavioral Interventions and Supports, both of which have been shown to prevent crime, drug and alcohol use, suicide ideation, and incarceration (Kellam et al., 2011). Unlike in his previous book, The Nurture Effect (Biglan, 2015), evidence-based academic interventions to "teach children well" (p. 79) are not addressed as frequently in Rebooting Capitalism. For instance, approaches such as Direct Instruction (DI; Stockard, Wood, Coughlin, \& Rasplica Khoury, 2018) and the Comprehensive Application of Behavior Analysis to Schooling (CABAS) system (Greer, 1997) have a strong literature base and have been demonstrated to be effective in improving student academic performance. Project Follow-Through, a U.S. Department of Education experiment with over 200,000 participants that spanned over a decade, underscored the benefits of Direct Instruction. Despite clear results, the public educational system did not change its practices nor utilize DI in significant ways (Watkins, 1997). Researchers in the field of special education found a correlation between literacy and high-school dropout rates and described literacy as a protective factor against a number of unfavorable outcomes, including high-school dropout (Reschly, 2010). Thus, widespread use of evidence-based, academic interventions could potentially alter rates of poverty and inequality, thereby contributing to a nurturing society.

The increased polarization of U.S. political rhetoric also warrants discussion. Although Biglan frequently alluded to individuals with conservative values (e.g., Donald Trump and the conservative billionaire coalition) throughout the book, the language used to describe and evaluate such individuals may function as aversive stimuli to those who identify as politically conservative. For instance, the introduction of the book begins, "America is in trouble. In the White House, we have a man who almost certainly will go down in history as our worst president. He has appointed many incompetent people, most of whom are working to make matters worse for the majority of Americans and ultimately the entire planet" (p. 5). This form of narrative could arguably result in conservative readers dismissing the book and prevent it from reaching a broader audience. As Biglan (2020) himself suggests, affirming people's values may increase the likelihood that they will be persuaded to agree with, or at least listen to, those who have opposing viewpoints on significant issues. Therefore, reframing the relations between verbal stimuli used to persuade conservative voters to follow the prosocial and nurturing agenda put forth by Biglan may have a more 
significant impact on how effectively our society can reboot capitalism, because conservative voters encompass a large sector.

An additional area for future consideration is the influence of artistic, literary, and intellectual activities on the well-being of a society. Skinner (1948) emphasized the importance of aesthetic reinforcers in daily life in his imagined utopian society, Walden Two. Unsustainable cultural practices were engineered out of the society, and the efficiency of labor practices were positively reinforced. Today, overconsumption of natural resources has made sustainability a key issue. To create a sustainable, steady-state society, Grant (2010) persuaded that we should address material overconsumption by increasing allocation of time spent with "resource-light and resource-free reinforcers," such as the performing, visual and literary arts (p. 14). Grant also suggested mainstream adoption of Bohemian values: a rejection of conventional economic materialism.

The Values to Action Coalition presents several opportunities as a starting point for new research aiming to change cultural practices. To begin, in order to recruit new members (including those outside of behavior analysis) to the coalition and promote values-based actions, a study of persuasive verbal behavior is warranted, particularly as it is presented in social media. We might ask, for example, how can relational framing be used to effectively establish prosocial values and evoke certain actions but not others from the populace? What types of formative or motivative augmentals are more likely to move people to action? Behavior economics may also help shine on a light on the levels of incentivization and taxation required to alter rates of consumer behaviors. For example, economists and behavior scientists agree that a carbon tax should be used to punish the act of burning of fossil fuels, but what level of tax is required to alter rates of behavior is not known. Behavior economic demand analysis may be useful in determining how demand elasticity shifts across varying tax rates, in accordance with Reed, Kaplan, Becirevic, Roma, and Hursh (2016), who assessed the demand of ultraviolet tanning across varying tax rates. Likewise, disinformation campaigns that flood the internet and social media sites establish a responsibility on the part of skilled teachers to teach discriminations between scientific and pseudoscientific information, or trustworthy versus untrustworthy information. The skill of distinguishing between fact and disinformation on the internet should be taught at all levels from pre-kindergarten through to higher education.

In sum, Rebooting Capitalism provides us with action steps to take towards a more cohesive, nurturing society. These steps are intended for all people, not just behavior analysts. However, in order to move forward in building a more nurturing society, behavior analysts must become an integral member of interprofessional units working to change the interlocking meta and macrocontingencies that govern cultural practices (Glenn et al., 2016). Rebooting Capitalism is a text that should be read by behavior analysts and could serve as useful supplemental reading for the Association for Behavior Analysis International's culturobehavior science (CBS; n.d.) course sequence, a means by which future behavior analysts are trained to apply behavior science to addressing large-scale societal issues through culture-wide interventions. There are several steps we can take to begin to the save the world. A first step is to read this book. A second step is to reach a broader audience. A third step is to join the Values to Action Coalition and begin committed action towards a values-driven culture. So, come on up for the rising (Springsteen, 2002), and reboot capitalism with the help of behavior science. 
Code Availability Not applicable

\section{Declarations}

Conflicts of Interest/Competing Interests The authors declare that they have no conflict of interest.

\section{References}

American Psychological Association. (2020). Stress in the time of COVID-19: Volume Two. Retrieved October 7, 2020, from https://www.apa.org/news/press/releases/stress/2020/report-june

Biglan, A. (2015). The nurture effect: How the science of human behavior can improve our lives and our world. New Harbinger Publications.

Biglan, A. (2016). The need for a more effective science of cultural practices. The Behavior Analyst, 39(1), 97-107.

Biglan, A. (2018). The ultimate goal of prevention and the larger context for translation. Prevention Science, 19(3), 328-336. https://doi.org/10.1007/s11121-016-0635-6.

Biglan, A. (2020). Rebooting capitalism: How we can forge a society that works for everyone. Values to Action.

Biglan, A., Ary, D. V., Smolkowski, K., Duncan, T., \& Black, C. (2000). A randomised controlled trial of a community intervention to prevent adolescent tobacco use. Tobacco Control, 9(1), 24-32.

Biglan, A., Johansson, M., Ryzin, M. V., \& Embry, D. (2020). Scaling up and scaling out: Consilience and the evolution of more nurturing societies. Clinical Psychology Review, 81, 1-12.

Brailovskaia, J., Schillack, H., \& Margraf, J. (2020). Tell me why are you using social media (SM)! Relationship between reasons for use of SM, SM flow, daily stress, depression, anxiety, and addictive SM use: An exploratory investigation of young adults in Germany. Computers in Human Behavior, 113, 106511.

Chan, S. C., Katz, B. D., Schmidt, D., \& Rehfeldt, R. A. (2020). "In” or “out?" An analysis of the use of augmentals in U.S. presidential speeches on the Paris Climate Agreement. [Manuscript accepted].

Cheng, J., Bernstein, M., Danescu-Niculescu-Mizil, C., \& Leskovec, J. (2017). Anyone can become a troll: Causes of trolling behavior in online discussions. CSCW: Proceedings of the Conference on ComputerSupported Cooperative Work, 2017, 1217-1230. https://doi.org/10.1145/2998181.2998213.

Cihon, T. M., \& Mattaini, M. A. (2019). Emerging cultural and behavioral systems science. Perspectives on Behavior Science, 42(4), 699-711. https://doi.org/10.1007/s40614-019-00237-8.

Conger, K., \& Isacc, M. (2021). Twitter permanently bans Trump, capping online revolt. The New York Times. Retrieved January 30, 2021, from https://www.nytimes.com/2021/01/08/technology/twitter-trumpsuspended.html

Critchfield, T. S., \& Reed, D. D. (2016). Does hearing about cancer influence stimulus control? An exploratory study of verbal modulation of stimulus generalization. Analysis of Verbal Behavior, 32(1), 46-59.

Daniels, A. C. (1989). Performance management. PM Publications.

Diller, J. D., \& Lattal, K. A. (2008). Radical behaviorism and Buddhism: Complementarities and conflicts. The Behavior Analyst, 31, 163-177.

Dixon, M. R., \& Lemke, M. (2007). Reducing prejudice towards Middle Eastern persons as terrorists. European Journal of Behavior Analysis, 8(1), 5-12.

Dixon, M. R., Rehfeldt, R. A., Zlomke, K. R., \& Robinson, A. (2006). Exploring the development and dismantling of equivalence classes involving terrorist stimuli. The Psychological Record, 56(1), 83-103.

Ehrlich, P. R., \& Kennedy, D. (2005). Millennium assessment of human behavior. Science, 309(5734), 562563.

Glenn, S. S., Malott, M. E., Andery, M. A. P. A. (2016). Toward consistent terminology in a behaviorist approach to cultural analysis. Behavior \& Social Issues, 25, 11-27. https://doi.org/10.5210/bsi.v.25i0. 6634.

Grant, L. K. (2010). Sustainability: From excess to aesthetics. Behavior \& Social Issues, 19(1), 7-47.

Greer, R. D. (1997). The comprehensive application of behavior analysis to schooling (CABAS®). Behavior \& Social Issues, 7(1), 59-63.

Harari, Y. N. (2014). Sapiens: A brief history of humankind. Random House.

Hayes, S. C. (2019). A liberated mind. Penguin. 
Hayes, S. C., \& Plumb, J. C. (2007). Mindfulness from the bottom up: Providing an inductive framework for understanding mindfulness processes and their application to human suffering. Psychological Inquiry, 18(4), 242-248. https://doi.org/10.1080/10478400701598314.

Hayes, S. C., \& Smith, S. (2005). Get out of your mind and into your life: The new acceptance and commitment therapy. New Harbinger Publications.

Holland, J. G. (1978). Behaviorism: Part of the problem or part of the solution. Journal of Applied Behavior Analysis, 11(1), 163-174. https://doi.org/10.1901/jaba.1978.11-163.

Holth, P. (2016). Levels of selection: A place for cultural selection. Norsk Tidsskrift for Atferdsanalyse, 43, 57-64.

Kellam, S. G., Mackenzie, A. C., Brown, C. H., Poduska, J. M., Wang, W., Petras, H., \& Wilcox, H. C. (2011). The good behavior game and the future of prevention and treatment. Addiction Science \& Clinical Practice, 6(1), 73.

Lillis, J., \& Hayes, S. C. (2007). Applying acceptance, mindfulness, and values to the reduction of prejudice: A pilot study. Behavior Modification, 31, 389-411.

Lueke, A., \& Gibson, B. (2015). Mindfulness meditation reduces implicit age and race bias: The role of reduced automaticity of responding. Social Psychological \& Personality Science, 6(3), 284-291.

Lueke, A., \& Gibson, B. (2016). Brief mindfulness meditation reduces discrimination. Psychology of Consciousness: Theory, Research \& Practice, 3(1), 34.

Malott, M. E. (2016). What studying leadership can teach us about the science of behavior. The Behavior Analyst, 39(1), 47-74.

Matsuda, K., Garcia, Y., Catagnus, R., \& Brandt, J. A. (2020). Can behavior analysis help us understand and reduce racism? A review of the current literature. Behavior Analysis in Practice, 13(2), 1-12.

Mattaini, M. A., \& Rehfeldt, R. A. (2020). Editorial: Rendezvous with truth and discovery. Behavior and Social Issues, 291-14. https://doi.org/10.1007/s42822-020-00034-y.

Meyerowitz, B. E., \& Chaiken, S. (1987). The effects of message framing on breast self-examination attitudes, intentions, and behavior. Journal of Personality \& Social Psychology, 52(3), 500-510.

Mizael, T. M., de Almeida, J. H., Silveira, C. C., \& de Rose, J. C. (2016). Changing racial bias by transfer of functions in equivalence classes. The Psychological Record, 66(3), 451-462.

National Aeronautics and Space Administration (NASA). (2019). Climate change evidence: How do we know? NASA.gov. Retrieved February 17, 2020, from https://climate.nasa.gov/evidence/

Normand, M. P., \& Bober, J. (2020). Health coaching by behavior analysts in practice: How and why. Behavior Analysis: Research \& Practice.

NSPC Coalition. (n.d.). What is prevention science? Retrieved October, 2020 https://www.npscoalition.org/ preventionscience

Pinker, S. (2018). Enlightenment now: The case for reason, science, humanism, and progress. Penguin Books.

Rakos, R. F. (1993). Propaganda as stimulus control: The case of the Iraqi invasion of Kuwait. Behavior \& Social Issues, 3(1-2), 35-62.

Reed, D. D., Kaplan, B. A., Becirevic, A., Roma, P. G., \& Hursh, S. R. (2016). Toward quantifying the abuse liability of ultraviolet tanning: A behavioral economic approach to tanning addiction. Journal of the Experimental Analysis of Behavior, 106(1), 93-106.

Rehfeldt, R. A., \& Tyndall, I. (2021). Why we are not acting to save ourselves: ACT, health, and culture. Behavior Analysis in Practice. (in press)

Reschly, A. L. (2010). Reading and school completion: Critical connections and Matthew effects. Reading \& Writing Quarterly, 26(1), 67-90.

Sanguinetti, A. (2012). The design of intentional communities: A recycled perspective on sustainable neighborhoods. Behavior \& Social Issues, 21(1), 5-25.

Skinner, B. F. (1948). Walden two. Macmillan.

Skinner, B. F. (1953). Science and human behavior. Macmillan.

Skinner, B. F. (1987). Why we are not acting to save the world. Upon further reflection, 1-14.

Springsteen, B. (2002). The Rising [CD]. Sony.

Stockard, J., Wood, T. W., Coughlin, C., \& Rasplica Khoury, C. (2018). The effectiveness of direct instruction curricula: A meta-analysis of a half century of research. Review of Educational Research, 88(4), 479-507.

Todd, A. R., Bodenhausen, G. V., Richeson, J. A., \& Galinsky, A. D. (2011). Perspective taking combats automatic expressions of racial bias. Journal of Personality \& Social Psychology, 100(6), 1027.

Vollmer, T. R. (2018). Differential reinforcement as a way of life [Paper presentation]. National Autism Conference: Pennsylvania State University, State College, PA, United States.

Volpp, K. G., Asch, D. A., Galvin, R., \& Loewenstein, G. (2011). Redesigning employee health incentives: Lessons from behavioral economics. New England Journal of Medicine, 365(5), 388-390. 
Watkins, C. L. (1997). Project Follow-Through: A case study of contingencies influencing instructional practices of the educational establishment. Behavior Monographs. Cambridge Center for Behavioral Studies. http://www.behavior.org

Wilson, D. S., O'Brien, D. T., \& Sesma, A. (2009). Human prosociality from an evolutionary perspective: variation and correlations at a city-wide scale. Evolution and Human Behavior, 30, 190-200.

Wilson, D. S. (2012). Consilience: Making contextual behavioral science part of the united ivory archipelago. Journal of Contextual Behavioral Science, 1(1-2), 39-42. https://doi.org/10.1016/j.jcbs.2012.09.005.

Wilson, D. S. (2016). Quality of life from an evolutionary perspective. Applied Research in Quality of Life, 11(2), 331-342.

Wine, B., \& Pritchard, J. (2018). Organizational Behavior Management: The Essentials. Orlando: Hedgehog.

Publisher's Note Springer Nature remains neutral with regard to jurisdictional claims in published maps and institutional affiliations. 